\title{
"Exporting" medical education
}

\section{Vinod Shah ${ }^{\mathrm{a}}, \mathrm{H}$ Elliott Larson ${ }^{\mathrm{b}}$, Nathan Grills ${ }^{\mathrm{c}}$, Daniel O’Neill ${ }^{\mathrm{d}}$, Michael Soderling ${ }^{\mathrm{e}}$}

\author{
${ }^{a}$ MD, Christian Medical College Vellore, India, Chairman, Int'l Christian Medical \& Dental Association \\ ${ }^{b} \mathrm{MD}, \mathrm{FRCP}, \mathrm{FIDSA}$, Editor-in-Chief, CJGH \\ ${ }^{c}$ MBBS, MPH, DPhil, Associate Editor, CJGH; Nossal Institute of Global Health, University of Melbourne, \\ Australia \\ ${ }^{d}$ MD, MA(Th), Managing Editor, CJGH; Assistant Professor of Family Medicine, University of Connecticut School \\ of Medicine, USA \\ ${ }^{e}$ MD, MBA, Associate Editor, CJGH, Chief Catalyst and Global Networker, Centre for Health in Mission
}

Transferring quality healthcare knowledge and skills across generations, disciplines, and cultures is a challenging endeavor. Four conference reports in this issue deal with efforts to provide assistance to medical education in low and middle income countries (LMIC). This has been a major effort by mainly North American physicians to improve the standards of medical teaching and practice in the developing world. The conferees met immediately prior to the Global Missions Health Conference in November, 2015, in Louisville, Kentucky, USA in four subgroups dealing with fostering undergraduate medical education, family and internal medicine residency training, surgical residency training, and recruitment of academic faculty to meet these opportunities. The conferees and the reports give background for, summarize current status of, and describe challenges and obstacles to these efforts.

The contributors to the pre-conference were individuals with extensive experience in medical education in North America, Africa, Latin America, and Asia. Their discussions showed awareness of the enormous challenges posed when attempting to deliver medical education in cross-cultural LMIC settings. A number of issues potentially important to the effort to provide medical education as medical mission deserve further elucidation and development. We propose to outline them here in the hope that ongoing discussions can take them up more fully.

\section{Critical Thinking and Participatory}

\section{Learning}

Medical education in LMICs affords challenges in teaching and learning techniques and styles. The focus of medical education in most LMICs seems to be delivering information rather than fostering comprehension. The fact that interactivity and asking questions is inappropriate in cultures where teachers are put on a pedestal compounds this problem. Comprehension is aided by "diffuse thinking" a process of "meditating" on the information and the concepts that have been delivered in the class room. It does not happen when you are keenly engaged with a single subject - a phenomenon called "focused thinking." Grappling with a math problem is an example of focused thinking; however, reflecting on the problem and integrating it with experience when walking is an example of diffuse thinking. The latter is what fosters comprehension. One can encourage diffuse thinking by asking students to complete a project after doing their own reading and reflecting. Such participatory approaches to medical education are important as it encourages comprehension and creativity. The conference report on Mobilizing and Training Academic Faculty for Medical Mission mentions training in interactive teaching methods as a goal in developing national medical educators.

Just because a teacher has taught does not make facts inviolable. Critical thinking, the need to challenge all the assumptions in the information that has been delivered is important. The Socratic approach, that is, teachers asking 
leading questions, helps students to analyze and evaluate information. Students asking teachers a lot of questions is counter-cultural in India and many LMICs; however, if this can be changed, their evaluation of and approach to real-life problems will be more effective.

Creativity is aided by the breadth in one's education. A mature medical student who has studied humanities is more likely to be creative and integrative than a narrow math/biology whiz kid. This has a basis in neuro-science. Among many other things, creativity is a function of being able to make connections in the brain between disciplines. Unfortunately, in most developing countries, the pursuit of medicine or other allied health professions is decided at a very early stage - as young as 16. After this, educational opportunities become more and more narrow. Influencing the teaching and learning methods in health-related education can greatly impact the quality of the average doctor, nurse, and public health professional in the developing world.

Taking bio-medical and public health knowledge and the approach to medical education from a high income country (HIC) and transferring it to low income settings without contextualization can be problematic at a number of levels. The transfer of medical education systems from high to low and middle income countries may not prepare health professionals for the context in which they work. Will they be prepared to work in an under-resourced indigenous setting with limited access to sophisticated diagnostic and treatment options? Or does training that is based on HIC models merely facilitate the "brain drain" of health professionals who emigrate to HICs? Do HIC standards of practice increase cost and further burden an already strained health system? Developing alternative, shorter, more focused medical courses not fully equivalent to physician training in HICs is an appealing option and has been attempted in LMIC settings. This should not mean training sub-par doctors, but the crossdisciplinary training of doctors, nurses, and others who are able to function well and lead in the system of the country where they will be practicing and in underserved areas where they may be needed the most. An example is Denis Burkitt's training of "dressers" in Uganda. These were individuals who could perform simple surgical procedures, but willing and able to work in rural and medically deprived areas. The problem is that most LMIC have already established medical training and curricula patterned on a Western reductionist and specialization paradigm. Attempting to change this expectation with a more contextualized, cross-disciplinary, and integrated approach adds another layer of complexity to the effort.

\section{Mutual Learning and Leadership}

Another requirement is to understand the importance of input from local leaders and indigenous health practitioners in LMIC. Their leadership for culturally-appropriate future educational efforts is highly desirable for capacity-building and sustainability. It is the hope that publication of the proceedings of the 2015 Louisville pre-conference in this issue will stimulate both interest and participation in future planning and conferences throughout the world. Transitions of leadership and empowerment can be a delicate process, and servant leadership models are particularly needed to avoid paternalism and neo-colonialism. Recognizing the limitations of short-term efforts to educate across cultures and between disparate health systems is to practice cultural humility. Mutual learning occurs by seeking first to understand, then to be understood (James 1:1). Thoughtful cooperation across cultures with multiple stakeholders is vital in planning effective learning environments.

\section{Professionalism and Ethics}

One issue that deserves further exploration is corruption. An education in medicine in a LMIC is a highly privileged opportunity. It can often be seen as entrée to preferment in government and business. This is one reason why some medical graduates do not continue in medicine; they may never have intended to have 
a career caring for the sick. Because of preferment status, admission to a medical education may be highly dependent on political and social connections. This can be a reason why the students who end up in a medical school may not always be the most suitable ones. Cheating on exams can be widespread and payment to teachers for improved grading common in many countries. ${ }^{1}$ This practice produces students compromised not only in their medical knowledge, but in the ethics they will use in approaching the care of patients. International campaigns against corruption in medicine have begun in countries like India, starting with ethics training in undergraduate curriculum, thus hoping for widespread global impact. $^{2}$

Gordon Hadley was a pathologist and dean of Loma Linda University School of Medicine from 1977 to 1986. Repeatedly over his professional career, he taught pathology to students in LMICs, with stints at Vellore Medical College, Kabul Medical University, and Nangrahar University in Jalalabad, Afghanistan. He even taught in Kabul when the Taliban were in control. Once, he told one of us (EL) that often there was no electricity, but the classes started on time! Gordon was of the firm conviction that Afghan students could learn well and become excellent doctors, but that integrity, missing from their education, had to become part of that experience. It was a battle with numerous fronts: the students themselves, the teachers and professors, and the government. He lost many of those battles despite his gracious and mild manner because the lack of integrity had a long history and reinforced personal privilege. After one faculty meeting in Jalalabad where he resisted altering the grades of failed students, the tires on the car of an expatriate faculty member were slashed. Early in the Karzai administration in Kabul, the president of the country himself lowered the passing grade from 50\% to $30 \%$, "just this time," to circumvent Dr. Hadley's standards. He instituted photo identification for admission to exams and caught two students taking exams for others. Not infrequently, his approach was opposed by non-Christian expatriates, in one case a Fulbright scholar, on the grounds that this was against the "the Afghan system."

Corruption may be the major issue in development. ${ }^{3}$ It is certainly key in education. Non-Christians can have a hard time "seeing" corruption. Pointing it out can involve unpleasant confrontations with local colleagues. But it is a matter of justice, and justice is an essential agenda for Christian witness. Medical education in LMIC often involves dealing with those countries' elites. This can call to mind Jesus' dealing with the elites of his time, the religious leaders and Roman authorities. His words to them were consistent. He never shirked from explaining and illustrating the truth to them. If as Christians we want to make a difference in health-related education in LMIC, can we do less?

\section{References}

1. Hrabak M, Vujaklija A, Vodopivec I, Hren D, Marušić M. Marušić A. Academic misconduct among medical students in a post-communist country. Med Educ. 2004;38:276-85. http://dx.doi.org/10.1111/j.1365-2923.2004.01766.x

2. Anita J, Samiran N,Kamran A.Corruption: medicine's dirty open secret. BMJ. 2014;348: g4184 http://dx.doi.org/10.1136/bmj.g4184

3. Heritage.org [Internet]. Washington, D.C.: The Heritage Foundation. Available from: http://www.heritage.org/index/explore

(C) Shah V, Larson HE, Grills N, O'Neill D, Soderling M This is an open-access article distributed under the terms of the Creative Commons Attribution License, which permits unrestricted use, distribution, and reproduction in any medium, provided the original author and source are properly cited. To view a copy of the license, visit http://creativecommons.org/licenses/by/4.0/

\section{www.cjgh.org}

Nov 2016. Christian Journal for Global Health, 3(2):3-5. 